\title{
BRIEF REPORT: THIN SLICES OF RACIAL BIAS
}

\author{
Jennifer A. Richeson and J. Nicole Shelton
}

\begin{abstract}
The present work examined the detection of racial bias through thin slices of nonverbal behavior. Thirty Black and 30 White American judges rated the nonverbal behavior displayed by White individuals from 20-seconds of silent videotape of an interaction with either a Black or a White confederate. Correlations between judges' nonverbal ratings and targets' scores on a response latency measure of racial bias (i.e., Implicit Association Test, IAT) as well as on a selfreport racial bias measure (i.e., Affective Prejudice Scale) were obtained. Results revealed that relative to White judges, Black judges' nonverbal behavioral ratings were better predictors of both White individuals' IAT and explicit racial bias scores, but only if those targets were engaged in an interracial dyad. The results are consistent with recent research finding that subtle forms of racial bias leak through nonverbal behavior, as well as with work noting the predictive accuracy of judgments made from thin-slices of nonverbal behavior.
\end{abstract}

KEY WORDS: Implicit Association Test; judgmental accuracy; nonverbal communication; racial bias; thin slices.

Extensive evidence suggests that people are impressively accurate at ascertaining many characteristics of others from minimal information. It has been found, for instance, that people can accurately judge both basic category memberships, such as age and sex, as well as personality traits, such as extroversion, on the basis of extremely brief interactions with strangers (e.g., Costanzo \& Archer, 1989; Kozlowski \& Cutting, 1977; Zebrowitz \& Collins, 1997; see also Ambady, Bernieri, \& Richeson, 2000 and Ambady \& Rosenthal, 1992 for reviews). Similarly, ratings from thin slices of nonverbal behavior-short segments of less than 5 minutes

Jennifer A. Richeson, Dartmouth College; J. Nicole Shelton, Princeton University. This research was supported by a Rockefeller Center Faculty Fellowship from Dartmouth College awarded to JR, as well as a research grant from Princeton University awarded to JNS. We thank Sue Paik, Lisa Pugh, Kurt Peters, and Leigh Poretzky for help with data collection and stimulus preparation.

Address correspondence to Jennifer A. Richeson, Department of Psychological and Brain Sciences, Dartmouth College, 6207 Moore Hall, Hanover, NH 03755; e-mail: jriches@ dartmouth.edu 
-have been found to be amazingly accurate predictors of sexual orientation (Ambady, Hallahan, \& Connor, 1999) and the biased expectations of teachers (Babad, Bernieri, \& Rosenthal, 1989). The purpose of the present research was to test whether racial attitudes, like other personality variables, can be detected accurately from extremely brief, thin slices of nonverbal behavior. That is, we examined the perceptual accuracy of racial bias detection.

\section{Leakage of Bias through Nonverbal Behavior}

Recent research attests to the ability of nonverbal aspects of communications to reveal racial attitudes that individuals are either unable or unwilling to report (Dovidio, Kawakami, \& Gaertner, 2002; Fazio, Jackson, Dunton, \& Williams, 1995; McConnell \& Leibold, 2001). For instance, White participants' nonverbal friendliness and discomfort with Black interaction partners were correlated with their implicit attitudes (e.g., Dovidio et al., 2002; Dovidio, Kawakami, Johnson, Johnson, \& Howard, 1997; McConnell \& Leibold, 2001). Similarly, four studies employing different measures of subtle racial bias each found that Whites' racial bias scores predicted how positively they were perceived by Black experimenters (Fazio et al., 1995; Dovidio, et al., 2002; McConnell \& Leibold, 2001; Sekaquaptewa, Espinoza, Thompson, Vargas, \& von Hippel, 2003). Considered in tandem, these studies underscore the ecological validity of employing thin-slice methodology to investigate the accuracy of racial bias detection.

\section{Individual Differences in Prejudice Detection}

According to functional theories, perceptual accuracy emerges because of the adaptive value for perceivers (e.g., Gibson, 1979; Zebrowitz \& Collins, 1997). Characteristics relevant to taking appropriate action relative to another individual are likely to be perceived quickly and accurately. For example, the ability to perceive emotions such as anger and fear quickly and accurately from still photographs is thought to stem from perceivers' needs to generate behavioral responses quickly and accurately (Ekman, 1973). Quite similarly, the ability to perceive the prejudice level of another individual would facilitate adaptive behavioral responses, particularly for members of racial minority or other stigmatized groups.

Consistent with this sentiment, there is some evidence that Black Americans are better able to perceive the prejudice level of White 
Americans, compared to other White individuals (Rollman, 1978). Rollman found that Black perceivers better discriminated among four White targets who differed in self-reported anti-Black prejudice from those targets' nonverbal behavior during a 3-minute interaction with a Black, compared to with a White, confederate. Prejudice has become relatively subtle since the Rollman (1978) study (see Dovidio et al., 2000), and it remains unclear whether these subtle forms of racial bias are also differentially detectable by Black relative to White perceivers; and, whether any form of racial bias can be gleaned from even briefer segments of the behavioral stream (20-seconds). Furthermore, in this earlier work, perceivers saw the race of the targets' interaction partners, which could have prompted them to look for cues to prejudice in the interracial interaction conditions. It is unclear whether Black perceivers would have been more accurate detectors of racial bias had they not been aware of the interracial or same-race context of the interaction. Consequently, the present work examined the accuracy with which Black and White perceivers could glean the racial bias of White targets that were engaged in either an interracial or a same-race dyadic interaction, without providing information regarding the racial demographics of the interaction. Because racial bias should leak more during interracial interactions than same-race interactions, we expected Black judges to detect the racial bias of White targets better than White judges, only if those targets were communicating with a Black individual (i.e., during interracial interactions).

\section{Present Study}

The present research examined the detection of two relatively subtle forms of racial bias in White individuals from a 20-second silent video clip of their nonverbal behavior during either an interracial interaction or a same-race interaction. Specifically, Black and White perceivers (judges) rated the global positive affect and prejudice revealed in the nonverbal behavior of White individuals (targets) during an interaction with either a White or a Black confederate. Correlations between judges' nonverbal behavioral ratings and targets' scores on a self-report measure of subtle racial bias, and a response latency measure of racial bias were used to assess judgmental accuracy. ${ }^{1}$ Based on the literature reviewed previously, we predicted that Black judges would be relatively more accurate than White judges at assessing the racial bias scores of White individuals during interracial dyadic interactions. 


\section{Method}

\section{Session 1: Creating Stimuli}

Targets. Forty-seven White students attending Dartmouth College served as targets in the present study. ${ }^{2}$ Targets were videotaped as part of a separate study examining cognitive consequences of interracial contact (Richeson \& Shelton, 2003). Participants engaged in a 5-minute videotaping session with one of four confederates (two Black and White) who posed as an experimenter for an ostensibly unrelated study. Participants first introduced themselves for about 1 minute and then were asked to comment on two issues each for about 2 minutes (the college fraternity system and racial profiling).

Creating stimulus tapes. The first 20 seconds from the videos of individuals sharing their views on the college fraternity system were extracted for each participant and compiled on a master tape. ${ }^{3}$ The extracted clips depicted the targets in the center of the screen, sitting in a large chair against a plain white background, talking to the confederate. The torso through the top of the head of the participant was visible, but, importantly, the confederate could not be seen in the clip. Clips were randomly ordered on the master tape.

Target automatic racial bias. Prior to the videotaping session, participants completed the Implicit Association Test (IAT; Greenwald, McGhee, \& Schwartz, 1998), as part of an ostensibly unrelated study. The IAT measures automatic associations, and has been employed in many studies to assess evaluations of racial groups (e.g., McConnell \& Leibold, 2001; Richeson \& Ambady, 2003). The IAT in the present study required participants to categorize White and Black names, and positive and negative words, as quickly as possible by pressing one of two response keys. After several blocks of introductory and practice trials, participants completed the first test block in which White names and positive words shared a response key, and Black names and negative words shared a key (White+/Black-Block). Then, the associations were reversed (White-/ Black+ Block) - White names and negative words shared a response key, and Black names and positive words shared a key. After 20 practice trials on the new association scheme, participants completed a second testing block. The order of presentation of these two testing blocks was counterbalanced across participants, and each testing block consisted of 40 trials. The difference between average latencies during the White+/Black- Block and average latencies during the White-/Black+ Block provided our 
JENNIFER A. RICHESON AND J. NICOLE SHELTON

index of each target's level of automatic racial bias. IAT bias scores ranged from -44-ms to +556-ms ( $M d n=315)$.

Self-reported racial bias was assessed by the Affective Prejudice Scale (Pettigrew, 1997), which a subset of targets had completed as part of a pre-testing session during the first week of classes $(N=41)$. Individuals indicated the extent to which they felt admiration, and the extent to which they felt sympathy for Blacks and for Whites on 5-point scales $(1=$ never to $5=$ frequently). The items were reversed scored and averaged for each race, reflecting targets' negative feelings regarding each group $(\alpha=.68$ and .73 for Black and White affective prejudice measures, respectively). We formed an index of self-reported racial attitude bias by subtracting self-reported affective prejudice for Whites from selfreported affective prejudice for Blacks. Scores ranged from -2.5 to +1.5 $(M d n=-0.57)$. Furthermore, preliminary analyses revealed a small correlation between the automatic and self-reported racial bias scores $(r(37)=.10)$ generated by the targets in the video clips examined in the present study.

\section{Phase 2: Judging Racial Bias}

Participants (judges) and procedure. Thirty White and 30 Black undergraduate students attending Princeton University served as judges in the present study for monetary compensation. Judges came in to the lab either alone or at the same time as one other individual (always of the same racial group), and individually watched and rated the nonverbal behaviors displayed by the targets. Each clip was presented without sound and judges did not know the race of the individual to whom the target was speaking or the content of the conversation. At the end of the rating session, judges completed a final questionnaire on which they self-identified their racial group membership, were debriefed, and paid $\$ 8$ for their participation.

Nonverbal rating. The present study considered whether racial bias could be gleaned from brief segments of White individuals' communications with either a White or a Black individual. Consistent with the methods reported in Dovidio et al. (2002), the interaction clips were rated according to how well several traits indicative of feelings of positivity or negativity and relative comfort described each target. Specifically, judges rated how cruel, likable, warm, pleasant, and friendly the targets appeared. In addition, several similar variables were also rated (i.e., tense, frightened, standoffish, rigid) in order to ensure the emergence of a reliable estimate of positive affect from these very brief clips. After 
appropriate reverse coding, ratings of all nine items were averaged to form an index of the extent of positive affect the target expressed in each clip. The positive affect composite was reliable for both the set of Black judges $(\alpha=.82)$ and for the set of White judges $(\alpha=.84)$. The single item "prejudiced" was also rated by the judges, and was examined separately from the composite, given its unique relevance to the focus of the present work. ${ }^{4}$ All ratings were obtained on 9 -point scales.

\section{Results}

The primary aim of the present work was to investigate individual differences in the detection of racial bias through thin slices of nonverbal behavior. Consistent with the data-analytic procedures outlined in Ambady et al. (1999), we computed the correlations between each judge's ratings of the targets' positive affect and prejudice and those targets' IAT bias scores and self-reported racial bias scores. These correlations provide a measure of the extent to which each judge rated targets with higher IAT and explicit racial bias scores as behaving less positively and/or with greater prejudice. ${ }^{5}$

\section{Automatic Racial Bias}

Positive affect ratings. The Fisher-transformed correlation coefficients between nonverbal positivity and participants' IAT bias scores were submitted to a 2 (Judge Race: Black, White) $\times 2$ (Dyad Racial Composition: same-race, interracial) mixed model ANOVA, with repeated measures on the second factor. Results revealed a statistically significant main effect of judge race, $F(1,58)=4.24, p=.04, r=.26$. Consistent with predictions, Black judges $(M=-.09, S D=.26)$, on average, were better able to glean the IAT bias scores of White targets, compared to White judges $(M=-.02, S D=.19)$. The main effect of dyad racial composition (i.e., whether the target was communicating with a Black or a White confederate) was also statistically reliable, $F(1,58)=106.7, p<.001, r=.80$. Judges were much better at detecting target IAT bias if those targets were communicating with a Black confederate $(M=-.20, S D=.18)$, rather than with a White confederate $(M=.09, S D=.17)$.

Although the interaction between judge race and dyadic racial composition was not statistically significant $(F(1,58)=2.35, p=.13, r=$ .19), we tested our a priori prediction that Black judges would indeed outperform White judges in the assessment of targets' racial bias if the targets 
were communicating with a Black confederate, but not if the targets were communicating with a White confederate. Consistent with predictions, Black judges' positivity ratings predicted IAT bias scores significantly better than those made by White judges, if those targets were communicating with a Black confederate (respective $M^{\prime} s=-.26$ and $-.15 ; t(58)=2.62$, $p=.02, r=.32$ ). By contrast, the accuracy of the positive affect ratings made by Black and White judges did not differ for targets communicating with a White confederate (i.e., targets of same-race dyads) (respective $M^{\prime} s=.08$ and $\left..10 ; t(58)=.45, p=n s\right)$. These results suggest that Black judges were able to detect Whites' automatic racial bias scores better than White judges, but only in contexts in which racial bias is more likely to leak through nonverbal behavior; namely, during interracial dyadic interactions.

Prejudice ratings. The Fisher-transformed correlation coefficients between nonverbal prejudice ratings and participants' IAT bias scores were also submitted to a 2 (Judge Race: Black, White) $\times 2$ (Dyad Racial Composition: same-race, interracial) mixed model ANOVA. Results revealed only the main effect of dyad racial composition, $F(1,52)=$ 4.76, $p=.03, r=.29$. Correlations associated with targets in interracial dyads $(M=.06, S D=.22)$ were larger than correlations associated with targets in same-race dyads $(M=-.03, S D=.21)$.

\section{Explicit Racial Bias}

Positive affect ratings. Similar to the analyses outlined previously for the detection of IAT bias scores, the Fisher-transformed correlation coefficients between nonverbal positivity and participants' explicit bias scores were submitted to a 2 (Judge Race: Black, White) $\times 2$ (Dyad Racial Composition: same-race, interracial) mixed model ANOVA. Results revealed no reliable effects, however (all $F^{\prime}$ s $<2$.).

Prejudice ratings. The Fisher-transformed correlation coefficients between judges' prejudice ratings and participants' explicit bias scores were submitted to the same 2 (Judge Race: Black, White) $\times 2$ (Dyad Racial Composition: same-race, interracial) mixed model ANOVA. Results revealed a trend for Black judges' ratings to predict explicit bias scores somewhat better than White judges, $F(1,54)=2.23, p=.14, r=.20$. Similarly, prejudice ratings of targets engaged in interracial dyads were marginally better predictors of their explicit bias scores than were prejudice ratings of targets engaged in same-race dyads, $F(1,52)=2.69, p=$ $.11, r=.22{ }^{6}$ The interaction between judge race and dyadic racial composition, however, was statistically reliable, $F(1,52)=4.83, p=.03$, 
$r=.29$. Consistent with hypotheses, Black judges' prejudice ratings predicted targets' explicit bias scores significantly better than those made by White judges, if those targets were communicating with a Black confederate (respective $M^{\prime} s=.18$ and $.07 ; t(53)=2.26, p=.03, r=.30$ ). By contrast, the accuracy of the prejudice ratings made by Black and White judges did not differ for targets communicating with a White confederate (respective $\left.M^{\prime} s=.07 \& .12 ; t(53)=1.03, p=n s\right)$. Considered in tandem with the results presented previously, these findings suggest that Black judges may have a perceptual advantage over White perceivers in the detection of racial bias from nonverbal aspects of the behavioral stream.

\section{Discussion}

A plethora of research documents the negative psychological impact that systematic prejudice and discrimination can have on members of stigmatized social groups (see Crocker, Major, \& Steele, 1998). One compelling side effect of long-standing racial oppression that has been proposed in the literature, is the chronic mistrust of Whites on the part of some members of racial minority groups (e.g., Terrell \& Terrell, 1981), manifesting in heightened awareness and vigilance, and perhaps, sensitivity to the presence of bias (Mendoza-Denton, Downey, Purdie, Davis, \& Pietrzak, 2002). Building on this work, and in replication of previous research (Rollman, 1978), the present study found that Black judges were relatively better than White judges at detecting the racial bias of White individuals from 20-second slices of their nonverbal behavior during an interracial interaction. Consequently, consistent with functional theories of perceptual accuracy, these findings suggest that systematic experiences with prejudice may result in at least one perceptual advantage, in addition to the many interpersonal costs documented previously (e.g., Mendoza-Denton et al., 2002).

\section{Nonverbal Manifestations of Prejudice}

There is a strong tradition in research on intergroup relations and prejudice to examine nonverbal aspects of behavior in order to assess prejudice (e.g., Dovidio et al., 1997, 2000; Fazio et al., 1995; McConnell \& Leibold, 2001; Sekaquaptewa et al., 2003; Weitz, 1972; Word, Zanna, \& Cooper, 1974). In the majority of this work, White coders have been used to assess bias, and have done so both reliably and accurately. At first glance it may seem that the present findings contradict this work. Several 
aspects of these studies differ from the present work, however, and are likely to account for the apparent differences. Most notably, we used extremely brief (20-seconds) clips of silent video, whereas previous research has employed longer segments of the behavioral stream (2 or 3 minutes). Furthermore, in contrast to some of this previous work, the judges in our study were naïve, rather than trained coders, and they had no information regarding the content or context of the conversation that the targets were engaged in. Similarly, in some research, judges rated the same target twice, allowing for a contrast between behavior with a White partner, and behavior with a Black partner. Our study allowed for no such contrast, making the task of detecting racial bias particularly challenging. Nevertheless, given the extant aforementioned research, we do not believe that our findings suggest that White judges are unable to glean racial bias from the nonverbal behavior of other White individuals, but, rather, that Black judges may have a perceptual advantage.

In addition to highlighting differences in the perceptual accuracy of Black and White judges, the present findings also suggest that automatic and explicit forms of racial bias may leak through different aspects of behavior. Consistent with previous research (i.e., Dovidio et al., 2002), we found that Black judges' ratings of how positively White targets behaved during an interracial dyad were negatively correlated with those targets' automatic racial bias scores, but not their self-reported racial bias scores. In contradiction to this work, but in replication of Rollman (1978), however, we found that Black judges' ratings of these same targets' level of prejudice from nonverbal cues predicted their self-reported racial bias scores, but not automatic racial bias scores. One possible explanation for this dissociation is that forms of racial bias that individuals are willing to report manifest in overt behaviors that are more easily categorized as prejudice, whereas automatic forms of racial bias manifest in a behavioral amalgam of discomfort, apprehension, and negativity (i.e., decreased global positivity). Additional research is necessary, however, in order to investigate relations among different forms of racial bias and their nonverbal manifestations.

\section{Conclusions}

In sum, the findings of the present study reveal that racial bias can be detected from 20 seconds of nonverbal behavior by Black perceivers, but only when the bias seems to be contextually relevant (i.e., during interracial interactions). Indeed, subsequent analyses revealed that as a set, Black judges' ratings of positivity and prejudice predicted the IAT bias 
and explicit bias scores, respectively, of White targets that were engaged in interracial dyads, at levels better than chance $(r(19)=-.45$ and $\left.r(17)=.46, p^{\prime} s=.05\right)$. We would like to be clear, however, that despite the statistical significance of the accuracy with which the set of Black judges detected these forms of racial bias, no single judge was $100 \%$ accurate. Such judgments are likely to be even more difficult to make during actual interracial interactions (e.g., Vorauer \& Kumhyr, 2001), given that many factors, including individuals' goals, influence their nonverbal behavior. Furthermore, it is not clear whether racial minorities actually attempt to judge the level and types of prejudice White interaction partners may have during interracial encounters. Nevertheless, the present findings suggest that if they so choose, they may do so with surprising accuracy.

\section{Notes}

1. To determine accuracy, we followed the methods used by previous research examining the detection of other aspects of personality and individual differences-that is, we used correlations between judgments of nonverbal behavior and the racial bias measures completed by the participants themselves (Funder, 1995).

2. Three clips were not extracted properly yielding the reduction of targets from the participant pool reported in Richeson and Shelton (2003).

3. We used the fraternity footage because it was race-neutral.

4. Two Black judges and three White judges did not complete any of the prejudice ratings, reducing the sample for this variable from 60 judges to 55. Furthermore, there was a substantial negative correlation between ratings of prejudice and the positive affect composite for both the set of White judges $(r=-.71, p<.001)$ and the set of Black judges $(r=$ $-.58, p<.01$ ). Analyses that include prejudice (reversed-scored) in the positivity composite yield the same pattern of results and nearly identical statistical values as those reported for the positivity composite alone.

5. Fisher's $z$ transformation of $r$ was used for analyses involving these correlations. However, for purposes of clarity, the results presented are re-transformed mean values of $r$.

6. The change in degrees of freedom is an adjustment due to missing observations.

\section{References}

Ambady, N., Bernieri, F., \& Richeson, J. A. (2000). Toward a histology of social behavior: Judgmental accuracy from thin slices of the behavioral stream. Advances in Experimental Social Psychology, 32, 201-271.

Ambady, N., Hallahan, M., \& Connor, B. (1999). Accuracy of judgments of sexual orientation from thin slices of behavior. Journal of Personality and Social Psychology, 77, 538547.

Ambady, N., \& Rosenthal, R. (1992). Thin slices of expressive behavior as predictors of interpersonal consequences: A meta-analysis. Psychological Bulletin, 111, 256-274. 
JENNIFER A. RICHESON AND J. NICOLE SHELTON

Babad, E., Bernieri, F., \& Rosenthal, R. (1989). Nonverbal communication and leakage in the behavior of biased and unbiased teachers. Journal of Personality and Social Psychology, 56, 89-94.

Costanzo, M., \& Archer, D. (1989). Interpreting the expressive behavior of others: The interpersonal perception task. Journal of Nonverbal Behavior, 13, 225-245.

Crocker, J., Major, B., \& Steele, C. M. (1998). Social stigma. In D. T. Gilbert, S. T. Fiske, \& G. Lindzey (Eds.), The handbook of social psychology (4th ed., Vol. 2, pp. 504-553). New York: McGraw-Hill.

Dovidio, J. F., Kawakami, K., \& Gaertner, S. L. (2000). Reducing contemporary prejudice: Combating explicit and implicit bias at the individual and intergroup level. In S. Oskamp (Ed.), Reducing prejudice and discrimination. 'The Claremont Symposium on Applied Social Psychology' (pp. 137-163). Mahwah, NJ: Erlbaum.

Dovidio, J. F., Kawakami, K., \& Gaertner, S. L. (2002). Implicit and explicit prejudice and interracial interaction. Journal of Personality and Social Psychology, 82, 62-68.

Dovidio, J. F., Kawakami, K., Johnson, C., Johnson, B., \& Howard, A. (1997). On the nature of prejudice: Automatic and controlled processes. Journal of Experimental Social Psychology, 33, 510-540.

Ekman, P. (1973). Cross-cultural studies in facial expression. In P. Ekman (Ed.), Darwin and facial expression: A century of research in review (pp. 169-222). New York: Academic Press.

Fazio, R. H., Jackson, J. R., Dunton, B. C., \& Williams, C. J. (1995). Variability in automatic activation as an unobtrusive measure of racial attitudes: A bona fide pipeline? Journal of Personality and Social Psychology, 69, 1013-1027.

Funder, D. C. (1995). On the accuracy of personality judgment: A realistic approach. Psychological Review, 102, 652-670.

Gibson, J. J. (1979). The ecological approach to visual perception. Boston: Houghton Mifflin.

Greenwald, A. G., McGhee, D. E., \& Schwartz, J. L. K. (1998). Measuring individual differences in implicit cognition: The Implicit Association Task. Journal of Personality and Social Psychology, 74, 1464-1480.

Kozlowski, L. T., \& Cutting, J. E. (1977). Recognizing the sex of the walker from a dynamic point-light display. Perception \& Psychophysics, 21, 575-580.

McConnell, A. R., \& Leibold, J. M. (2001). Relations between the Implicit Association Test, explicit racial attitudes, and discriminatory behavior. Journal of Experimental Social Psychology, 37, 435-442.

Mendoza-Denton, R., Downey, G., Purdie, V. J., Davis, A., \& Pietrzak, J. (2002). Sensitivity to status-based rejection: Implications for African American students' college experience. Journal of Personality and Social Psychology, 83, 896-918.

Pettigrew, T.F. (1997). Generalized intergroup contact effects on prejudice. Personality and Social Psychology Bulletin, 23, 173-185.

Richeson, J. A., \& Ambady, N. (2003). Effects of situational power on automatic racial prejudice. Journal of Experimental Social Psychology, 39, 177-183.

Richeson, J. A., \& Shelton, J. N. (2003). When prejudice does not pay: Effects of interracial contact on executive function. Psychological Science, 14, 287-290.

Rollman, S. A. (1978). The sensitivity of black and white Americans to nonverbal cues of prejudice. The Journal of Social Psychology, 105, 73-77.

Sekaquaptewa, D., Espinoza, P., Thompson, M., Vargas, P., \& von Hippel, W. (2003). Stereotypic explanatory bias: Implicit stereotyping as a predictor of discrimination. Journal of Experimental Social Psychology, 39, 75-82.

Terrell, F., \& Terrell, S. L. (1981). An inventory to measure cultural mistrust among Blacks. Western Journal of Black Studies, 5, 180-184.

Vorauer, J. D., \& Kumhyr, S. M. (2001). Is this about you or me? Self- versus other-directed judgments and feelings in response to intergroup interaction. Personality and Social Psychology Bulletin, 27, 706-709. 
JOURNAL OF NONVERBAL BEHAVIOR

Weitz, S. (1972). Attitude, voice, and behavior: A repressed affect model of interracial interaction. Journal of Personality and Social Psychology, 24, 14-21.

Word, C. O., Zanna, M. P., \& Cooper, J. (1974). The nonverbal mediation of self-fulfilling prophecies in interracial interaction. Journal of Experimental Social Psychology, 10, 109-120.

Zebrowitz, L. A., \& Collins, M. A. (1997). Accurate social perception at zero acquaintance: The affordances of a Gibsonian approach. Personality and Social Psychology Bulletin, 3, 204-223. 